\title{
A Obscuridade do Poético em Paul Celan
}

\author{
Obscurity of Poetry in Paul Celan
}

Mauricio Mendonça Cardozo ${ }^{1}$

\begin{abstract}
Tensioned between variations of the said and the unsaid, and between figures of light and shadow, Paul Celan's work performs a certain confrontation with the condition of silence and obscurity, breaking all at once with a certain way of making poetry and of relating to reality. In this sense, Celan's work can hardly be reduced to a kind of hermeticism, a category too vague to account for its singularity. In his work saying and silencing together articulate the tension that creates the poetic space in which the poem is inscribed. The poet himself tried to refuse the insistence of some critics on labeling his work as obscure. Despite of its fragmentary nature, the recently published manuscripts of his speech project Von der Dunkelheit des Dichterischen constitutes one of Celan's most extensive discussions of the matter of obscurity in poetry. This paper aims at presenting the fragments of his speech project and pointing out its importance to the discussion of the notion of obscurity in Paul Celan's work.
\end{abstract}

Key-words: Paul Celan; contemporary Poetry; Obscurity; Hermeticism

Resumo: A partir da tensão entre variações do dito e do não-dito e entre figuras de luz e sombra, a obra de Paul Celan performa um certo enfrentamento da condição de silêncio e de obscuridade - de onde seu estigma como obra hermética -, rompendo, a um só tempo, com um certo modo de fazer poesia e de se relacionar com a realidade. Nesse sentido, a obra de Celan não se deixaria resumir a uma espécie de hermetismo, categoria demasiadamente vaga para dar conta da singularidade de sua obra. Em sua obra, dizer e calar seriam, antes, os termos de articulação de uma relação que instaura o espaço poético em que se inscreve o poema. Em diversas ocasiões o próprio poeta tentaria refutar a insistência de alguns críticos em rotular sua obra como obscura. A despeito de seu caráter fragmentário, o manuscrito recém-publicado de seu projeto de conferência intitulado Sobre a obscuridade do poético constitui uma das discussões mais extensas de Celan sobre a questão da obscuridade na poesia. Este trabalho tem por objetivo apresentar esse conjunto de fragmentos de seu projeto de conferência e apontar sua importância para a discussão da noção de obscuridade na obra de Paul Celan.

Palavras-chave: Paul Celan - poesia contemporânea - obscuridade - hermetismo

\footnotetext{
${ }^{1}$ Professor de teoria da tradução e literatura alemã do Curso de Letras: Bacharelado em Estudos da Tradução e do Programa de Pós-graduação em Letras da Universidade Federal do Paraná. Pesquisador do CNPq. Email: maumeluco@uol.com.br
} 
Cardozo, M. M. - A obscuridade do poético em Paul Celan

Nós mesmos [os orientais] somos incapazes de compreender por que o jade, que não tem o vívido colorido de um rubi ou de uma esmeralda, nem o brilho de um diamante, tanto nos seduz [...].

Junichiro Tanizaki ${ }^{2}$

Um homem é escuro, no meio do luar da lua - lasca de breu.

Guimarães Rosa ${ }^{3}$

Há, penso eu, aquém e além de todo esoterismo e hermetismo, aquém e além de saberes secretos e de revelações, há uma obscuridade do poema.

Paul Celan ${ }^{4}$

Falar da obscuridade na obra de Paul Celan ${ }^{5}$ pressupõe a discussão da questão da obscuridade na poesia em geral, o que, por sua vez, pressupõe a discussão de uma longa tradição crítica, construída no entorno das várias questões da poesia moderna e contemporânea. Essa tradição remonta a um imenso corpus de obras poéticas e de reflexões poetológicas que se empenham em discutir o estatuto da poesia desde, pelo menos, meados do século XVIII, mas também a sínteses hitórico-críticas que encontrariam grande repercussão ao longo do século XX, como a obra de Hugo Friedrich, Die Struktur der Modernen Lyrik (FRIEDRICH 2006, publicado originalmente em 1956), para mencionar aqui apenas um dos exemplos mais óbvios. No esboço dessa tradição, surgem também inúmeros pontos de resistência, zonas de sombra, visões alternativas, enfim, outros lugares da crítica e da poesia que vão se estabelecendo à diferença das vertentes críticas mais dominantes. E é nesse embate entre o que se configura como um conjunto de visões mais disseminadas de poesia e as que persistem

\footnotetext{
${ }^{2}$ TANIZAKI 2007: 22.

${ }^{3}$ RosA 1988.

4 "Es gibt, denke ich, dieseits und jenseits von aller Esoterik und Hermetik, dieseits und jenseits von Geheim- und Offenbarungswissen, eine Dunkelheit des Gedichts." (CELAN 2005: 134, fragmento 245, grifo do autor, tradução minha). Os textos originalmente escritos em língua alemã e citados aqui em português, salvo menção em contrário, são traduções minhas.

${ }^{5}$ Uma versão preliminar deste texto foi apresentada no XI Congresso Internacional da ABRALIC, em 2008.
} 
como visões alternativas, que surgem vários dos desdobramentos hoje candentes na crítica e na poesia contemporânea, lugar em que também se inscreve a obra e a reflexão poetológica de Paul Celan.

Seja pelas limitações de tempo e espaço, seja pelo horizonte mais discreto pretendido para esta reflexão, não se propõe, aqui, um tour de force que explore a complexidade do tema em sua ampla extensão, tarefa que poderia ser cumprida mais adequadamente no contexto de um projeto de pesquisa de maior fôlego. Trata-se aqui de um trabalho de natureza mais ensaística, que não pretende, senão, chamar a atenção do leitor para a existência de um conjunto importante de manuscritos até pouco tempo ainda inéditos e apontar para sua relevância no contexto da discussão crítica da obra celaniana, com especial atenção à discussão do estatuto de obscuridade a que a obra de Celan frequentemente é associada.

O primeiro movimento deste ensaio propõe-se como uma breve apresentação do conjunto de fragmentos de Sobre a obscuridade do poético, destacando sua relevância para a rediscussão do estatuto de obscuridade da obra de Celan. O segundo movimento constrói um pequeno recorte da recepção crítica da obra de Celan no Brasil e em Portugal, com o intuito de mostrar, ainda que a partir de um recorte bastante reduzido da fortuna crítica do autor em língua portuguesa, como se dão, na tradição crítica que nessas terras lusófonas se esboça, as adesões e as refrações à tendência de enquadramento de Celan num paradigma que associa a obscuridade de sua obra a diferentes formas de hermetismo. Em seguida, partindo da reflexão que o escritor japonês Junichiro Tanizaki faz em seu ensaio Em louvor da sombra (TANIZAKI 2007), um terceiro movimento propõe-se como breve digressão sobre o lugar da sombra no mundo moderno. Nesse sentido, a passagem pelo ensaio de Tanizaki não tem por objetivo desenvolver, aqui, um estudo comparativo entre os mundos oriental (japonês) e ocidental, tampouco pretende colocar em relação as obras do escritor japonês e do poeta de língua alemã. Para os fins deste ensaio, interessa apenas a problematização que Tanizaki faz de dois modos diferentes de relação com os domínios do obscuro. O quarto movimento faz um mergulho rápido na obra poética de Celan, para mostrar como a obscuridade não é apenas tema de sua reflexão crítica, mas também uma questão candente em sua poesia. Por fim, num movimento que se pretende menos como 
conclusão do que como esboço do lugar de uma discussão que aqui apenas se inicia, propõe-se uma retomada da figura da sombra como morada, presente no ensaio de Tanizaki, no horizonte de discussão da obscuridade como lugar da poesia de Celan.

\section{$1 \bigcirc$ poema e o obscuro nos fragmentos de Sobre a obscuridade do poético}

“O poema, enquanto poema, é obscuro; e é obscuro porque é o poema”, 6 anota o poeta Paul Celan (1920-1970) num dos 140 pequenos fragmentos, esboçados provavelmente em 1959, por ocasião da preparação de uma conferência que levava, então, o título provisório de Sobre a obscuridade do poético (Von der Dunkelheit des Dichterischen). Em outro dos fragmentos, o poeta retoma sua primeira formulação, despindo-a agora da carga tautológica: "O poema é obscuro, antes de mais nada, pelo modo como se faz presente [por seu Vorhandensein], pelo modo como se faz objeto [por sua Gegenständlichkeit], pelo modo como objeta [por sua Gegenständigkeit]; portanto, é obscuro no sentido de uma opacidade fenomenal, já que própria de todo objeto; no sentido, portanto, de que o poema quer ser entendido, a partir de si mesmo, como um algo presente". 7

Hans Jürgen Leep, responsável pelo convite e pela organização do evento em que Celan faria a conferência encomendada, expõe abertamente, em carta endereçada ao poeta, as expectativas em relação a sua fala:

Eu já ficaria contente se, ao unirmos nossas forças, conseguíssemos deixar claro para alguns leitores de poesia contemporânea o quê, em princípio, há por trás da suposta e autêntica obscuridade na arte de hoje; e que é errado pensar o

\footnotetext{
6 "Das Gedicht ist als Gedicht dunkel, es ist dunkel, weil es das Gedicht ist." (CELAN 2005: 132, fragmento 242.2, grifo do autor).

7 "'Dunkel' ist das Gedicht zunächst durch sein Vorhandensein, durch seine Gegenständlichkeit, ständigkeit; dunkel also im sinne einer jedem Gegenstand eigenen, mithin phänomenalen Opazität; in dem Sinne also, dass es von sich her, als ein Vorhandenes verstanden sein will" (CELAN 2005: 137, fragmento 248.2, grifo do autor).
} 
Cardozo, M. M. - A obscuridade do poético em Paul Celan

incompreendido, sempre e em toda parte, como uma palavra cruzada que se tornou difícil demais. ${ }^{8}$

A conferência, afinal, não se realizaria. Todavia, em sua unidade de projeto de conferência que não teve lugar, esse conjunto ${ }^{9}$ de fragmentos representa (cf. CELAN 2005: 636) a porção mais antiga do conjunto de manuscritos a que remonta $O$ Meridiano, ${ }^{10}$ discurso proferido por ocasião da entrega do Prêmio Georg Büchner, em 1960, e que representa uma das mais importantes reflexões poetológicas do poeta. Os inúmeros fragmentos de Sobre a obscuridade do poético seriam reunidos e publicados postumamente. Primeiramente de modo mais esparso, em 1999, no contexto da edição crítica de $O$ Meridiano, organizada por Bernhard BösCHENSTEIN e Heino SCHMULL (CELAN 1999). Em seguida, como parte integrante da edição comentada dos textos em prosa do espólio de Celan, Mikrolithen sinds, Steinchen: die Prosa aus dem Nachlass, organizada por Barbara WIEDEMANN e Bertrand BADIOU (CELAN 2005: 130-152, fragmentos 240 a 267) e publicada em 2005. ${ }^{11}$ Algo desses fragmentos ecoa no famoso discurso de Celan: "Senhoras e Senhores, é comum, hoje em dia, repreenderem a poesia por sua 'obscuridade', ${ }^{12}$ E algo desses fragmentos - figuras, temas, formulações -

\footnotetext{
8 "Ich wäre schon froh, wenn es uns mit vereinten Kräften gelänge, einigen Lesern zeitgenössischer Dichtung klar zu machen, was es mit der vorgeblichen und echten Dunkelheit in der heutigen Kunst ,prinzipiell' für eine Bewandtnis hat, und dass es falsch ist, das Unverstandene immer und überall aufzufassen als ein zu schwierig geratenes Kreuzworträtsel.” (CELAN 2005: 635-636, grifos meus)

${ }^{9}$ Datados do ano de 1959, segundo a edição crítica de Barbara Wiedemann e Bertrand Badiou (CELAN, 2005: 635-637), esse conjunto de fragmentos teria sido reunido, pelo próprio poeta, numa pasta com a rubrica Von der Dunkelheit des Dichterischen. Em outro fragmento, uma pequena lista de prováveis projetos por acabar, datada de junho de 1960 (CELAN 2005: 113, fragmento 193), Celan inclui um ensaio sobre a "Obscuridade", o que nos dá notícia do horizonte que Celan vislumbrava para esses manuscritos.

${ }^{10}$ Der Meridian (Celan 2000: 187-202). Em seu posfácio à publicação de Arte Poética: O Meridiano e outros textos (CELAN 1996a), antologia portuguesa de textos em prosa de Paul Celan, João Barrento já apontava, em 1996, a existência desse conjunto de manuscritos: "O texto definitivo de 'O Meridiano' é o resíduo da decantação difícil de um manuscrito enorme (notas, transcrições, tentativas, entre maio e outubro de 1960), com cerca de trezentas páginas à espera de divulgação, o que só acontecerá depois de saído o volume respectivo da edição histórico-crítica em curso de publicação." (João Barrento in: CELAN 1996a: 78). O tradutor refere-se à edição crítica de Tübingen (Tübinger Ausgabe), que seria publicada três anos mais tarde. (Cf. CELAN 1999).

${ }^{11}$ No contexto de um estudo de maior fôlego, caberia cotejar as diferentes edições críticas, estabelecidas segundo diferentes critérios de edição.

12 "Meine Damen und Herren, es ist heute gang und gäbe, der Dichtung ihre 'Dunkelheit' vorzuwerfen" (CELAN 2000: 195). No contexto mais restrito deste artigo, não cabe senão destacar a existência de relações importantes entre os fragmentos de Sobre a obscuridade do poético e textos mais conhecidos, como $O$ Meridiano. Na medida em que muitas das formulações e figuras do projeto de conferência resurgem de diversas formas em textos tão importantes do poeta, como em $O$ Meridiano, os fragmentos aqui apresentados parecem constituir objeto de inestimável valor crítico não apenas para a discussão da
} 


\section{Cardozo, M. M. - A obscuridade do poético em Paul Celan}

repete-se, em inúmeras variações, ao longo de toda sua obra poética e epistolar. É notória, por exemplo, a frequência com que o poeta articula figuras polares da luz e da escuridão, explorando nuances óticas que, ao invés de se firmarem num desses extremos - da ausência ou presença total da contraparte -, tendem frequentemente a uma zona espectral sem limite nítido: à sombra, à contraluz, ao opaco, ao lusco-fusco e ao arrebol.

Nos fragmentos que integram seu projeto de conferência, Celan insistirá longamente na tese da obscuridade como o domínio do poético, mas não sem marcar uma diferença entre o que ele e a crítica compreendem por obscuro. O poeta afirma referir-se a uma obscuridade constitutiva do poema, o que ele entende ser diferente das obscuridades festejadas por certa "filologia que triunfa sob os aplausos dos diletantes". ${ }^{13}$ Diferente, portanto, de uma obscuridade com a qual a crítica relacionaria sua própria obra; diferente de uma obscuridade produzida, de uma obscuridade do poema difícil, fechado, impermeável, de uma obscuridade do sentido enigmático, oculto ou, até mesmo, de uma obscuridade do sem sentido. Para Celan, isso tudo não passaria do produto de cabeças por demais eruditas e obscuras; e não apenas das cabeças de sua ou de nossa época, já que, segundo o poeta, sempre houve esses homens obscuros de grande erudição. $^{14}$

A essa equação - a partir da qual começa a definir-se uma especificidade do obscuro na obra de Celan, que, já a essa altura, parece colocar em perspectiva alguns discursos da crítica de ontem e de hoje - o poeta acrescenta ainda outro elemento, o da abertura, que Celan não parece entender como um negativo da obscuridade, ao contrário:

\footnotetext{
Mesmo o poema mais exotérico, mesmo o poema mais aberto - e eu acho que hoje, particularmente em alemão, são escritos poemas por vezes declaradamente porosos, absolutamente translúcidos - tem sua obscuridade e a tem enquanto poema; mesmo o poema mais aberto, porque é o poema, vem obscuro ao
}

\footnotetext{
questão da obscuridade do poético, mas também para uma releitura mais ampla desses textos e para a continuidade da discussão da obra poética e poetológica de Celan, em geral.

13 "Und ich spreche auch nicht von jenen Dunkelheiten, die eine unter dem Beifall der Dilettanten triumphierende 'Philologie' - ich wollte, man könnte dieses Wort in diesem Zusammenhang klein schreiben - über das Gedicht feiert, [...]" (CELAN 2005: 134, fragmento 245).

14 "Es gibt diese hochgebildeten Dunkelmänner, hat sie immer gegeben; [...]" (CELAN 2005: 134, fragmento 245 , grifo meu).
} 


\section{Cardozo, M. M. - A obscuridade do poético em Paul Celan}

mundo. Portanto, uma obscuridade congênita, constitutiva, é o que o poema tem hoje. $^{15}$

Para Celan, o poema é obscuro; a obscuridade lhe é natural, "congênita". Mas que obscuridade seria esta, que habita o poema até mesmo em sua mais expressiva clareza?

A despeito de a noção do obscuro e a ideia de poema aberto surgirem aqui em relação, a questão da abertura, ao menos do ponto de vista temático, é ainda embrionária nesses fragmentos. Em seus escritos posteriores, porém, essa questão toma vulto - em especial como vocação dialógica - e também se torna termo de oposição à discussão do hermetismo (cf. Perez 2005: 14). A tese de doutorado de Juliana P. PEREZ, intitulada Poemas abertos: um estudo sobre A Rosa de Ninguém, de Paul Celan [Offene Gedichte: Eine Studie über Paul Celans Die Niemandsrose] (PEREZ 2005 e 2010) disponível, por ora, apenas em língua alemã -, dá a dimensão da importância dessa questão na obra do poeta. Perez reconstitui com precisão e rigor os principais momentos e tendências da recepção da obra de Celan dos anos 50 até hoje, em especial no que diz respeito ao que a autora chama de uma mudança de paradigma crítico: de uma visada hermética para uma visada dialógica. Ao distanciar-se tanto de uma noção de abertura ligada à ideia de polissemia e indeterminação quanto de certa noção de abertura ligada à ideia de veracidade - poesia em sua relação "direta" com a realidade -, Perez propõe uma discussão da noção de abertura em quatro níveis diferentes - linguístico, cognitivo, ético e poetológico -, produzindo, assim, um redimensionamento crítico - tanto no plano temático quanto no plano estrutural - desse conceito no contexto da recepção da obra de Celan, em especial do livro A Rosa de ninguém. ${ }^{16}$

Para Celan, a despeito do que a crítica insistisse em apontar, a ideia de uma obscuridade do poema não estaria ligada a uma determinada forma de percepção do hermético, no sentido do impenetrável, do esotérico, do secreto ou do cifrado. Celan assume uma posição clara a esse respeito, como já se pode perceber na epígrafe que

\footnotetext{
15 "Auch das exoterische, auch das offenste Gedicht - und ich glaube, dass heute, zumal im Deutschen, auch solche, stellenweise sogar ausgesprochen poröse, durchaus lichtdurchlässige Gedichte geschrieben werden - hat seine Dunkelheit, hat sie als Gedicht, kommt, weil es das Gedicht ist, dunkel zur Welt. Eine kongenitale, konstitutive Dunkelheit also, die das Gedicht heute hat." (CELAN 2005: 139, fragmento 251.3)

${ }^{16}$ Die Niemandsrose, livro de poemas publicado originalmente em 1963. Vide a edição crítica: CELAN 1996b.
} 


\section{Cardozo, M. M. - A obscuridade do poético em Paul Celan}

abre este trabalho: "Há, penso eu, aquém e além de todo esoterismo e hermetismo, aquém e além de saberes secretos e de revelações, há uma obscuridade do poema" (CElan 2005: 134, fragmento 245). No entanto, essa obscuridade, enquanto característica constitutiva do poema, não se apresenta como um fator limitador da leitura e da compreensão, e, sim, como sua própria condição de existência. Segundo o poeta:

[...] o poema quer ser entendido, e quer ser entendido justamente porque é obscuro: obscuro como poema, poema enquanto obscuro. ${ }^{17}$ Todo poema demanda, portanto, compreensão, demanda um querer entender, um aprender a entender $[\ldots] .{ }^{18}$

Nesses termos, a obscuridade do poema se apresentaria menos como dificuldade do que como uma demanda específica: pressuporia, tanto na relação com leitores e críticos quanto na relação com o próprio espaço do poema (como poema), um modo muito particular de acontecer, de ter lugar, ${ }^{19}$ em que a obscuridade se apresenta como traço irredutível da poesia e, portanto, como dimensão constitutiva da singularidade da poesia entendida nesses termos. Para Celan, o obscuro aproxima-se, assim, do singular: é o singular na e da poesia. O obscuro é o que a poesia tem de próprio. $\mathrm{O}$ obscuro é o que, no poema, resiste (a uma leitura ou a um modo de ler, a uma expectativa ou a um modo de lidar com horizontes de expectativa, a uma tradição ou a um modo de se relacionar

\footnotetext{
17 Opto, aqui, pela versão parafrástica "poema enquanto obscuro", que traduz minha leitura do neologismo Gedichtdunkel (composição entre o substantivo neutro Gedicht, poema, e o substantivo neutro Dunkel, no sentido de escuridão, obscuridade). Nessa passagem, Celan insiste em afastar-se da ideia de obscuridade como algo produzido ou atribuído ao poema. Sua ênfase parece recair sobre uma escuridão, uma obscuridade fundante do poema. Portanto, o poema, para Celan, faz-se poema porque fundado na obscuridade. Seu neologismo se afasta, assim, de uma relação atributiva entre o poema e o obscuro: na formulação "poema obscuro", que Celan parece evitar - de fato, Celan não usa em parte alguma de seus fragmentos a formulação atributiva "das dunkle Gedicht" -, persiste a ideia de que o obscuro é impressão, é atributo. Para Celan, diferentemente, a obscuridade é expressão do poema. E o poema é expressão, justamente porque obscuro. Daí a síntese neológica do Gedichtdunkel: o poema quer ser entendido em sua poescuridão de poemobscuro. Vale lembrar que Celan se vale do substantivo Gedicht também para a composição de outras formas neológicas, como Gedichtzu e Gedichtauf. (CELAN 2003: 515)

18 "[...] das Gedicht will verstanden sein, es will gerade, weil es dunkel ist verstanden sein -: als Gedicht, als 'Gedichtdunkel'. Jedes Gedicht erheischt also Verständnis, Verstehenwollen, Verstehenlernen [...]" (CELAN 2005: 132, fragmento 242.2, grifos do autor)

${ }_{19}$ Celan se refere em diversos fragmentos a uma concepção de poema como acontecimento ("Geschehen", "Geschehnis": vide, por exemplo: CELAN 2005: 97, fragmento 162.2; 101, fragmento 165.4; 151, fragmento 267.4.), concepção que, neste ensaio, ganha corpo na forma de um "ter lugar", de um "acontecer" do poema.
} 
com a tradição) e, por isso mesmo, é o que constrói o poema em sua singularidade. ${ }^{20} \mathrm{~A}$ singularidade do poema não é algo obscuro que se impõe, como uma obscuridade pretendida, construída e, portanto, em grande medida, controlada. Obscuro é o que no e do poema se expõe como singularidade: "La poesie ne s'impose plus, elle s'expose", registraria Celan em 26.03.69 (CELAN 2000: 181)

Cabe lembrar, aqui, que as ideias poetológicas de Celan não se propõem no vazio, marcando, antes, uma diferença em relação a certas visões mais disseminadas da poesia e da crítica literária nas décadas de 50 e 60 do século XX. Isso é especialmente válido no que diz respeito a uma visão de poesia como "arte pura", dominante na cena da poesia alemã na década de 50, a partir de uma matriz que remonta à síntese valéryana da "poésie pure" 21 e que encontraria em Gottfried Benn - no ideal do poema absoluto e numa poética monológica - um de seus maiores epígonos. ${ }^{22}$ Nesse sentido, é preciso ler as reflexões poetológicas de Celan também como contraponto crítico, à luz e à sombra dessa visão de poesia.

É nesse sentido que, se para Gottfried Benn, num poema tudo se dá sempre como "questão do eu, e todas as esfinges e os véus da figura da deusa Saïs se misturam na resposta", 23 para Celan, o poema não se articula pelo afã da dedução ou da solução de enigmas, na medida em que a obscuridade, como a singularidade (do poema, do outro, do eu), não quer, nem pode ser resolvida, solucionada. A obscuridade se apresenta, antes, como demanda do outro, como desafio de convivência. Fazendo alusão à obra do filósofo Max Scheler, Celan faz um contraponto com o princípio segundo o

\footnotetext{
${ }^{20}$ Essa passagem é tributária da relação que Marcos Siscar, a propósito da leitura-tradução do poeta Tristan Corbière, estabelece entre o que resiste na tradução-leitura de um poema e aquilo que constrói o poema em sua singularidade: "A resistência do texto traduzido, a ser retirado de sua língua, de si mesmo, é a resistência que retém a atenção sobre aspectos que lhe são essenciais e específicos. [...] Nesse sentido, as resistências que o texto original opõe à leitura dão lugar a uma experiência de tradução que é sempre única e que deve trazer em seus critérios mais gerais a marca da singularidade de seu objeto." (SISCAR 1996: 32. Vide também: SISCAR 2011)

${ }^{21}$ Refiro-me, aqui, ao desenho que Valéry propõe para uma tradição que encontra um ponto de partida em Baudelaire, sob impacto de Poe, e que se desdobraria exemplarmente nas obras de Verlaine, Rimbaud e Mallarmé. Vide a esse respeito, entre outros: VALÉRY (2007: 21-31, em especial); BARBOSA (2007: 93-95, entre outras).

${ }_{22}$ Paradigmática dessa visão é a obra Probleme der Lyrik [Problemas da lírica], de Gottfried Benn, publicada em 1951. Na biografia que escreveria sobre Celan, John Felstiner sintetizaria: "Benn optou "pelo poema absoluto, pelo poema sem crença, pelo poema sem esperança, pelo poema que não se dirige a ninguém'." (FELSTINER 2000: 153)

23 "Ein Gedicht ist immer die Frage nach dem Ich, und alle Sphinxe und Bilder von Sais mischen sich in die Antwort" (BENN 1986: 67, grifo meu)
} 
qual recorremos ao que já é conhecido para entendermos o que é relativamente desconhecido. Segundo o poeta: "Quem quer explicar poemas assim, está perdendo de vista o fato de que a direção que se segue a caminho do 'desconhecido' é, ela mesma, constitutiva desse desconhecido". ${ }^{24}$ Para Celan, o poema não se funda no cálculo e na sistematização. Se para Benn, “o poema já está pronto antes mesmo de começar, ele [o poeta] só não encontrou ainda seu texto", ${ }^{25}$ Celan é categórico ao afirmar: "Nenhuma silogística, ainda que adensada por alguma teoria associativa, nenhuma logística poderá jamais fazer jus ao 'poema' enquanto factum - o suposto esquema mental ou linguístico do poema nunca fica 'pronto'.,26

Se, para Benn, "só muito raramente um poema surge - um poema é feito", 27 para Celan, o poema não pode ser reduzido à discussão de um fazer. Vale lembrar que as discussões em torno do fazer do poema como ofício e das condições de possibilidade de um fazer poético na contemporaneidade não são questões menores para Celan, do que dão dimensão, entre outros bons exemplos, a Carta a Hans Bender [Brief an Hans Bender] (CELAN 2000: 177-178), enviada a seu antologista e publicada em 1961, bem como vários dos fragmentos publicados na edição crítica dos textos em prosa do espólio do $^{20 e t a .}{ }^{28}$

Para Celan: “[...] o poema não será nunca o resultado da maestria de seu respectivo poeta, independentemente da grandeza e excelência dessa maestria"; ${ }^{29}$ ou ainda, "o feitio [Machart, no sentido tanto do modo como é feito quanto do modo como se apresenta] não explica o poema". ${ }^{30}$ Vistas como contraponto a certa visão de poesia, essas afirmações não significam um descaso do poeta com as especificidades do fazer poético, como poderíamos ser levados a crer se as tomássemos isoladamente. Antes,

\footnotetext{
24 "Wer Gedichte so erklären will, der verliert aus den Augen, dass die Richtung, auf der der Weg zu 'Unbekannt' erfolgt, dieses Unbekannt mit konstituiert." (CELAN 2005: 135, fragmento 246.5, grifo do autor)

25 “[...] das Gedicht ist schon fertig, ehe es begonnen hat, er weiss nur seinen Text nicht” (BENN 1986: 68)

26 "Keine um irgendeine Assoziationstheorie bereicherte Syllogistik, keine Logistik wird dem Faktum 'Gedicht' jemals gerecht werden können - das vermeintliche Denk- oder Sprachschema des Gedichts ist niemals 'fertig'". (CELAN 2005: 131, fragmento 241.7, grifo do autor)

27 "Ein Gedicht entsteht überhaupt sehr selten - ein Gedicht wird gemacht" (BENN 1986: 66, grifos meus)

${ }^{28}$ Vide, especialmente, o conjunto de fragmentos reunidos sob o título de "Theoretische Prosa" (CELAN 2005: 93-176), de que fazem parte também os fragmentos de Sobre a obscuridade do poético.

29 "Denn das Gedicht kann nie das Resultat der Meisterschaft des jeweiligen Dichters sein, so Gross und bewährt diese Meisterschaft auch sein mag" (CELAN 2005: 102, fragmento 166). O fragmento em questão integra o conjunto de manuscritos a que remonta a Carta a Hans Bender.

30 “[...] die Machart erklärt das Gedicht nicht [...]". (CELAN 2005: 137, fragmento 248.3, grifo meu)
} 
Cardozo, M. M. - A obscuridade do poético em Paul Celan

representam um modo de pontuar sua não adesão a uma compreensão do fazer do poema como algo que se encerra em si: a tensão dialógica da poesia celaniana, que se projeta declaradamente no sentido de um outro, de um você (um tu), impõe-se como forte contraste à visão "monológica", "anacorética" (BENN 1986: 67) da poesia de Benn e de seu círculo de repercussão.

É, enfim, como contraponto a essa visão de poesia que, para Celan, o poema não se propõe como simples manifestação de uma lógica da arte pela arte, não se fecha numa compreensão do poema como o mero "resultado de alguma espécie de expressão artística", ${ }^{31}$ ou mesmo, como poésie pure ${ }^{32}$.

Essas características, entre outras, dimensionam ex negativo uma forma particular do poético, um ter lugar do poema que não se propõe nem nos mesmos termos do que está dado numa certa tradição da poesia (cf. CELAN 2005: 150), nem no mesmo espaço que essa tradição tem lugar. Como contraponto a outra visão de poesia, os fragmentos de Sobre a obscuridade do poético nos dão notícia do modo como Celan parece entender que o poema não se dá. Sua obra poética e alguns de seus escritos poetológicos, por outro lado, dão mostras de como o poema tem lugar.

Para Celan, o ter lugar do poema pressupõe um trabalho, pressupõe um esforço voltado para a conquista de um lugar no mundo e de seu lugar no mundo da poesia contemporânea (cf. a esse respeito CARDOZO 2008). Talvez por isso sua obra tenha encontrado, e ainda encontre, tanto resistência quanto interesse da parte de leitores, críticos e estudiosos de poesia mundo afora. A recepção crítica de sua obra, nesse sentido, é tão reveladora das diferentes facetas da poética celaniana quanto dos próprios modos e lugares da crítica que a toma por objeto: a recepção crítica da obra de Celan é tão reveladora daquilo que, em sua obra, insiste em se construir como poema, quanto daquilo que, na crítica, resiste a sua leitura.

\footnotetext{
31 "Das Gedicht ist keineswegs, wie manche glauben, das Ergebnis irgendeiner 'Ausdruckskunst"”. (CELAN 2005: 145, fragmento 260.3)

32 "Das Gedicht heute ist keine Poésie pure". (CELAN 2005: 146, fragmento 262.1)
} 


\section{Amostragem crítica: alguma recepção crítica no Brasil e em Portugal $^{33}$}

No capítulo introdutório de sua tese de doutorado, Juliana P. PEREz (2005: 15-39) faz uma longa discussão do repertório crítico em torno da obra de Celan - com foco especial na fortuna crítica em língua alemã -, demarcando duas grandes linhas de força em sua recepção: a primeira, ligada ao que Perez chama de o paradigma do hermetismo, que marcaria a recepção de Celan desde suas primeiras publicações nos anos 50 e seria fortemente influenciada pelo impacto, na Alemanha, da obra Die Struktur der Modernen Lyrik [A Estrutura da Lírica Moderna], de Hugo FRIEDRICH (2006); a segunda, bem mais recente, ligada ao que Perez chama de o paradigma da abertura, que se manifestaria, em alguns casos, como reação clara a uma visada hermética da obra de Celan e, em outros, simplesmente como proposta de uma nova perspectiva de leitura, sem, no entanto, romper com o pressuposto do hermetismo (PEREZ 2005: 15).

No Brasil, salvo engano, é provável que uma das primeiras contribuições para a recepção da obra de Celan tenha sido uma resenha de Modesto Carone, publicada em edição de agosto de 1973, no jornal Folha de São Paulo, e que inclui uma tradução sua, para o português, do poema Todesfuge (CELAN 2004: 55-59). ${ }^{34}$ Em seu texto, Carone chama a atenção do leitor para o desafio que a leitura de Celan representaria, em razão

\footnotetext{
${ }^{33}$ A recepção crítica de Celan no Brasil e Portugal é relativamente discreta se levarmos em consideração a produtividade crítica de sua obra e o lugar que Celan ocupa no contexto da crítica internacional. Todavia, aos poucos o poeta vem ganhando espaço no mundo lusófono. Este ensaio faz apenas um recorte mínimo dessa recepção. No Brasil, a lista de pesquisadores que vêm se dedicando ao estudo e à tradução do poeta é bem mais ampla. Para além dos trabalhos citados no corpo do texto, gostaria de lembrar ainda de alguns nomes importantes, como Márcio Seligmann-Silva, Susana Kampf Lages, Adalberto Müller, Nelson Ascher, Guilherme Gontijo Flores, Artur Ataíde e Raquel Abi-Sâmara.

${ }^{34}$ A despeito de tratar-se do poema mais conhecido (e mais traduzido) de Celan, pouca atenção é dedicada (ao menos na crítica lusófona) ao fato de que, em sua edição definitiva, como parte integrante do livro Mohn und Gedächtnis (CELAN 2004), publicado originalmente em 1952 (e, em edição comercial, em 1953), Todesfuge constitui, por si só, um dos quatro ciclos desse livro de poemas. Trata-se, portanto, de um poema-ciclo. A importância da figura do ciclo de poemas como elemento articulador da unidade do livro-de-poema na obra de Celan já foi amplamente reconhecida e estudada pela crítica (vide, por exemplo, o trabalho de Juliana P. PEREZ, 2005 e 2010). E, no caso particular desse poema, a questão não é de menor importância para o poeta, como atesta a carta escrita a sua editora em novembro de 1952: "TODESFUGE é um poema autônomo, i.e, um poema que deve ser visto como um ciclo autônomo." [TODEFUGE ist ein selbständiges Gedicht, d. j. als selbständiger Zyklus zu betrachten] (CELAN 2004: 55)
} 
das dificuldades "que seus textos francamente obscuros e 'herméticos' oferecem aos dissecadores de toda poesia 'difícil'" (CARONE 2008).

Se, nessa breve apresentação do poeta, Carone subscreve à tendência dominante da recepção celaniana nos anos 70 e 80 , em A poética do silêncio, sua tese de livre docência, publicada em 1979, o autor parece apontar para a necessidade de uma problematização da dimensão do hermetismo em Celan. Para Carone, o poeta estaria na mesma linha de tradição que remonta a Baudelaire, Mallarmé e Valéry. Nesse sentido, ao promover no próprio tecido verbal uma sondagem do estatuto da poesia, os poemas de Celan poderiam ser entendidos como crítica da linguagem. Crítica que não se daria no corpo de um discurso filosófico ou científico, mas no próprio espaço do poema, como meta-poema (CARONE 1979: 16). Carone elegeria o silêncio na obra de Celan como elemento que justifica a impressão "das dificuldades que sua dicção poética fechada [...] oferece à leitura" (Id.: 17). Para o autor: "Essa vocação para o silêncio é, na verdade, uma das marcas fundamentais da poesia de Celan - o impulso que a leva conscientemente ao hermetismo" (Id.: 19). Carone identificaria, aí, uma convicção do poeta "de que a poesia radica no espaço do não-dito" (Id.: 21). No entanto, a despeito de identificar em Celan essa inequívoca "marcha para o silêncio" (Id.: 21) - acentuada ainda mais em seus últimos livros -, Carone aponta para uma necessidade de se pensar numa "versão mais complexa" (Id.: 99) dessa obscuridade celaniana, ressaltando que seu hermetismo "não se confunde com esteticismos do tipo arte-pela-arte ou torre-demarfim" (Id.: 100).

Não se pode deixar de mencionar também as duas antologias da obra de Celan traduzidas por Flávio Kothe - Poemas (CELAN 1977); Hermetismo e Hermenêutica (CELAN 1985) - e que representam as duas primeiras edições de poemas de Celan publicadas no Brasil. Trata-se de um trabalho inserido de modo emblemático no chamado paradigma do hermetismo, no qual o tradutor encontra justificativa para o próprio trabalho de tradução, na medida em que resume sua motivação tradutória à “necessidade" de transpor "a barreira do hermetismo" (KOTHE in CELAN 1977: 11).

Essa visada hermética não se restringe, porém, à recepção da obra celaniana nos anos 70 ou 80. Em Portugal, Maria João Cantinho, ao resenhar a então recém lançada tradução do livro Sete Rosas Depois, (publicada em 1996, na tradução de J. Barrento e 
Y. K. Centeno), refere-se a Celan como um poeta marcado por um "hermetismo judaico-cabalístico", destacando uma "ausência de luz da sua poesia" (CANTINHO 2006). Em resenha mais recente, intitulada Paul Celan: no rastro perdido da experiência, CANTINHO (2010) parece aproximar a ideia de experiência dos limites do real e da linguagem a um limiar do emudecimento. Mesmo desenvolvendo sua reflexão na esteira da dimensão ética da relação com o outro implicada no tempo dessa experiência limite, sua leitura do poeta articula-se ainda centralmente em torno do eixo do hermetismo. Ao final de sua resenha, CANTINHo (2010) afirma:

\footnotetext{
Não existe qualquer apaziguamento nessa poesia de um hermetismo que revela um mundo irreversivelmente contaminado, destruído. O hermetismo - e o cabalismo - da sua poesia reforça, através das suas imagens, esse esvaziamento do mundo e, ao mesmo tempo, permite a acentuação da intensidade dramática do real.
}

No Brasil, em 1999, Erwin Rosenthal, ao resenhar a então recém lançada antologia de poemas de Celan, traduzidos por Claudia Cavalcanti, associa o hermetismo a questões problematizadas pelo viés da Literatura de Testemunho, ao dizer que "O mundo hermético dos textos revela a perplexidade do poeta perante a incomensurabilidade da experiência humana" (RoSENTHAL 2006). Além disso, define também uma espécie de jogo a ser jogado pelos leitores e pela crítica, ao descrever a obra de Celan como marcada por uma "expressividade muitas vezes críptica, cuja decifração, ainda que conotativa, se impõe" (Id.).

A partir dos anos 90, como bem destaca Perez, a crítica especializada passa a dispor de edições histórico-críticas de sua obra poética e em prosa, bem como de edições até então inéditas de sua vasta correspondência e dos textos esparsos que integram o espólio do poeta (material de que também nos servimos aqui). É visível o impacto que essas publicações vêm provocando na crítica mais recente, tanto promovendo a rediscussão de questões a muito tematizadas quanto levantando novas questões e perspectivas de abordagem da obra de Celan. Também a discussão sobre a questão do hermetismo na obra de Celan sofreria um redimensionamento significativo.

Em "Paul Celan: a expressão do indizível” (ARON 1997), Irene Aron analisa o famoso poema Todesfuge, de Celan, no horizonte de uma espécie de estética do indizível, destacando os recursos técnicos utilizados pelo poeta - como a repetição 
Cardozo, M. M. - A obscuridade do poético em Paul Celan

incessante de topoi da tradição lírica, que o poeta transforma em Leitmotive do poema para a construção de um monumento de homenagem às vítimas da Shoah, sem recorrer a imagens de "câmaras de gás ou de fornos crematórios" (ARON 1997: 85). Trata-se, para Aron, do indizível não no sentido de uma negatividade, do que se fecha a uma passagem ao dito - a autora sublinha, ao contrário, o uso que Celan faz de uma linguagem "relativamente simples" (Id.: 82). Para a autora, ao menos no que diz respeito à obra do jovem poeta autor de Todesfuge, trata-se, antes de mais nada, de um modo singular de dizer o indizível.

Ao discutir traduções portuguesas que exploram o espólio do poeta, Antonio GUERREIRO (2006) identifica a questão do hermetismo como uma discussão que teria sido produzida pela crítica, chamando a atenção para o fato de que Celan não se via nada satisfeito com o epíteto de poeta hermético. Tendo em vista suas reflexões poetológicas, Guerreiro põe em questão a aproximação de Celan com o paradigma mallarmaico e chega mesmo a se perguntar: "como uma poesia tão intensamente em busca da realidade poderia ser hermética?" (Id.).

Já no ensaio de Vera LiNs (2005), intitulado Paul Celan, na quebra do som e da palavra:... (publicado originalmente em 1998), a autora brasileira promove a tese de que a poesia de Celan "faz um percurso em que a linguagem é levada a seus abismos, desarticulada e rarefeita", mas sem capitular diante de seus limites. Ao contrário, Lins sublinha o fato de que essa linguagem sempre aponta para a possibilidade de "uma redescoberta das palavras e da existência" (Id.: 23). Para a autora, a obra de Celan "tem lugar no reencontro, o que, no entanto, só pode acontecer pela travessia dos abismos da linguagem" (Id.).

A poética celaniana estaria, assim, a serviço de flagrar a linguagem em sua espessura, despertando-nos de um sonho de transparência. Para Lins, Celan faz isso ao optar por "um modo de dizer que arruína a representação" (Id.: 24), quando "opera com a carbonização e o esvaziamento da escrita; quebra o ritmo e a sintaxe, trabalha com pedaços de sons e palavras, cunha novas palavras, divide outras" (Id.: 26) e assim por diante. Tendo isso em vista, Lins aproxima Celan dos simbolistas franceses, na medida em que sua poesia, como a deles, poderia ser entendida como recusa, como "crítica radical à linguagem da comunicação" (Id.: 27). 
Cardozo, M. M. - A obscuridade do poético em Paul Celan

Em certos momentos, como ao definir o trabalho do poeta como um ofício "de extrema precisão e quase silêncio" (Id.: 25), a reflexão de Lins revela-se, em certa medida, tributária da tese de Carone, cuja obra a autora cita e discute. Lins reforça a tese de que a obra de Celan parece tornar "impossível a tarefa de produzir um sentido" (Id.: 28). No entanto, a autora descreve o "ato poético" celaniano como algo que "nega o que é pelo corte, pela quebra, pela aniquilação da aparência" (Id.: 30). Nesses termos, tal impossibilidade de fazer sentido não diria respeito a uma impermeabilidade, a um fechamento da obra sobre si mesma, a um suposto hermetismo, mas sim, a uma espécie de ruptura instaurada no espaço do poema, que Lins identificará como o momento em que a poesia acontece, como o "instante da catástrofe ou da revolta, quando das ruínas emerge um dizer inesperado" (Id.: 32). Esse corte seria um traço marcante da poesia de Celan, para quem, segundo a autora, "a poesia é interrupção, suspensão da fala [...] Quando a palavra falta, acontece a poesia" (Id.: 33). Nesse sentido, a obra de Celan, ao empenhar-se na "quebra de um mundo para poder fazer emergir o não dito" (Id.), encenaria uma recusa à lógica da representação.

Mais recentemente, os estudos celanianos no Brasil foram saudados com a importante publicação da obra A dor dorme com as palavras (OLIVEIRA 2011), trabalho de fôlego de Mariana Camillo de Oliveira, resultado de sua dissertação de mestrado, intitulada A dor dorme com as palavras: a poesia de Paul Celan nos territórios do indizível e da catástrofe (OLIVEIRA 2008). Em sua dissertação, a autora problematiza tanto a redução da poesia de Celan ao estigma do hermetismo, quanto certa compreensão da figura da abertura dialógica, avançando a discussão da questão do indizível ao confrontá-la com a discussão dos limites da representação da catástrofe. Oliveira trabalha extensivamente com a ideia da incorporação do silêncio ao falar, ou, em outras palavras, compreende o silêncio como uma forma do dizer. Para OLIVEIRA (2008: 142), enfim:

[...] o conflito e a ambivalência desta ideia devem ser sustentados para não se reduzir a poesia celaniana ao fechamento obscuro e silencioso do hermetismo (do absolutamente incomunicável) ou à abertura dialógica e comunicativa de uma linguagem que pode abarcar (se tudo é dito, o diálogo inexiste. Falar demais também pode ser um crime, que torna Auschwitz digerível, que, por superestetizá-lo, torna-o impossível de ser percebido). 


\section{Morada das sombras}

Em seu belo ensaio escrito em 1933 e intitulado Em louvor da sombra, o escritor japonês Junichiro Tanizaki esboça uma breve fisiognomia da cultura japonesa. ${ }^{35} \mathrm{Em}$ especial, chama-lhe a atenção o modo como alguns elementos da modernidade ocidental - como a luz elétrica - começavam a tomar conta do cotidiano japonês, substituindo formas tradicionais - como a iluminação a óleo ou a luz de vela -, ao invés de constituírem novas formas híbridas, como uma possível mescla entre o ocidente e um certo oriente. Tendo por objeto os mais diversos elementos que integram tradicionalmente o universo cotidiano de sua cultura - como papel, tigelas laqueadas, painéis sutilmente ornados com detalhes em ouro, latrinas, luminárias, a arquitetura dos templos e das residências, o teatro Nô, entre outros -, Tanizaki reflete sobre o lugar da sombra, do opaco e da penumbra no mundo japonês, à diferença do que, segundo o autor, ocorreria no mundo ocidental, marcado pelo signo da luz, da transparência e do brilho.

Para Tanizaki, o Ocidente não teria se inclinado a apreciar o escuro, o obscuro, o opaco e o sombrio (TANIZAKI 2007: 47). O autor observa que até mesmo os fantasmas, na tradição ocidental, seriam claros ou transparentes como o vidro, enquanto, na tradição japonesa, sua característica mais dominante seria a de não terem pés. Os orientais apreciariam a turbidez do jade e as cores escuras, compostas de inúmeras camadas de sombras, enquanto os ocidentais prefeririam a transparência pura dos cristais e as cores claras, compostas por camadas de luz solar. Os japoneses teriam em alta estima os objetos oxidados pelas mãos do homem e pelo tempo, enquanto os ocidentais os lustrariam até vê-los cintilar.

Para o escritor japonês, essa propensão às sombras, no mundo oriental, estaria ligada a uma determinada concepção de beleza. Segundo Tanizaki, para os orientais "a beleza inexiste na própria matéria, ela é apenas um jogo de sombras e de claro-escuro

\footnotetext{
${ }^{35}$ No contexto deste ensaio, interessam particularmente as figuras de pensamento de Tanizaki, em especial na medida em que criam uma perspectiva diferente para a discussão do lugar das sombras no mundo contemporâneo. Idiossincrasias e limitações da visão do ensaísta, especialmente no que diz respeito à complexidade das relações entre um certo oriente e um certo ocidente, não serão discutidas aqui.
} 
Cardozo, M. M. - A obscuridade do poético em Paul Celan

surgido entre matérias" (Id.: 46). Expostos à claridade intensa, os objetos se resumiriam a sua superfície, perdendo vida pela "ausência de contraste" (Id.: 29). Mas quando na penumbra, iluminados pela luz baça das antigas lanternas e luminárias, os objetos revelariam sua profundidade, sua densidade (Id.: 25), seus contornos, sua singularidade.

Para Tanizaki, esta seria a chave do "mistério das sombras" na cultura oriental. Ao invés de afastá-las da casa, ao invés de eliminá-las, iluminando-as com o brilho espalhafatoso da luz elétrica, como tenderiam a fazer os ocidentais num ímpeto de modernidade, os japoneses teriam aprendido a conviver com e nas sombras, cultivandoas a ponto de se tornarem traço constitutivo e indissociável do espaço que habitam: se as sombras fossem banidas dos cômodos da casa, a casa "reverteria de imediato à condição de simples espaço vazio" (Id.: 35). Portanto, no mundo oriental o espaço da morada se definiria como um domínio do sombrio. Ao comparar as igrejas ocidentais aos templos orientais, TANIZAKI (2007: 30) afirma:

Sou totalmente leigo em matéria de arquitetura, mas, segundo me dizem, a beleza das igrejas de estilo gótico reside em suas torres altas, muito altas e pontiagudas, quase a tocar o céu. Ao contrário, um templo em nosso país começa a ser construído pela cobertura, ampla e revestida de pesada telha; e na sombra densa limitada pelo beiral recolhemos toda a edificação.

As casas ocidentais também têm telhado; mas, para o escritor, o telhado no mundo ocidental estaria antes a serviço da proteção da chuva, do frio e do sereno do que propriamente a serviço da proteção da luz do sol. No mundo oriental, segundo Tanizaki, "ao construirmos uma residência, abrimos antes de mais nada um guarda-sol - o telhado - sobre a terra, isto é, nela projetamos um pedaço de sombra, e nesse espaço escuro e sombrio construímos a casa." (Id.: 30).

\section{Um ter lugar de escuro em escuro: a sombra e o poema}

Ainda que se explicite aqui certa resistência ao viés de leitura de Celan como poeta hermético, não se trata de investir numa defesa do viés dialógico, nem de propor um 
confronto entre as duas visadas, tampouco de pôr em questão a legitimidade dessas linhas de força da recepção celaniana.

O tão referido hermetismo da obra de Celan tem seu lugar na medida em que se entende como expressão crítica, como sintoma de uma espécie de quebra de expectativa, do contraste entre a poesia de Celan e uma visão de poesia que mais engrandece as formas puras da arte, seu caráter monológico ou seu poder declarativo, fundado no primado da legibilidade e avesso a disforias e aporias de qualquer espécie resguardadas aqui todas as imprecisões e os pontos-cegos dessas categorias.

É preciso rever o estatuto hermético dessa obra, porém, quando se reduz esse hermetismo a certa "dificuldade de compreensão" dos poemas de Celan. Os elementos lexicais mais recorrentes na obra do poeta, os Leitmotive que gravitam no espaço de sua obra formando uma espécie de "mitologia pessoal" - de que fala Beda ALLEMANN (1987: 7) -, são de uma coloquialidade explícita e tendem a privilegiar o concreto ao abstrato: noite, sombra, luz, árvore, olho, palavra, pedra, boca, nome, água. Ao contrário do que uma primeira impressão possa fazer crer, sua linguagem é predominantemente coloquial - vale lembrar que grande parte de sua obra se constrói num registro próximo ao do diálogo. Essa base de coloquialidade é entrecortada por seus não tão raros, mas contundentes neologismos, por suas atomizações, pelo uso eventual de expressões ou termos arcaicos e, em especial, pela elipse. Essas tensões de fato rompem, interrompem a fala em sua dinâmica cotidiana, suspendem a leitura, criando desvios, hiatos e, por sua vez, a dimensão de obscuridade e mistério tão característica da obra do poeta. No entanto, tais tensões só representam de fato uma "dificuldade de leitura" na medida em que os poemas sejam lidos em face de um horizonte de expectativa fundado na matriz de uma visão de poesia diferente da que propõe o próprio poeta. O obscuro, aí, é o que de singular sua obra oferece, para além de um lugar da poesia que já está dado e se constitui como um horizonte de expectativa bem estabelecido. O obscuro, em Celan, é a expressão de uma recusa a inscrever sua obra nesse lugar; e, ao mesmo tempo, é expressão da insistência do poeta num fazer do poema, mas entendido em outros termos. A obra de Celan nos convida justamente para algo que tem lugar na ruptura do 
automatismo de nossas expectativas. É nesse sentido que o poema “demanda, portanto, compreensão, demanda um querer entender, um aprender a entender". ${ }^{36}$

A obscuridade do poema, em Celan, inscreve o poético como domínio das sombras. Em "Fale você também" [Sprich auch Du], ${ }^{37}$ poema do livro De limiar em limiar [Von Schwelle zu Schwelle], originalmente publicado em 1955 (CELAN 2002: 102-103), lemos um verso emblemático dessa defesa da obscuridade:

\author{
Fale - \\ Mas não separe o Não do Sim. \\ Dê a tua fala também o sentido: \\ dê-lhe a sombra. ${ }^{38}$
}

A sombra, no entanto, não é a escuridão absoluta, o silêncio sem contornos e que nada carrega, a falta de sentido: na condição de escuridão absoluta, não há sombra que se projete. E também não há sombra que se projete na pretensa condição de luz total, de claridade absoluta. A sombra não se funda numa binariedade da ausência e da presença de luz, do Não e do Sim. A sombra é justamente o espaço que se instaura entre o claro e o escuro, o espaço em que convivem luz e escuridão. É na sombra que a palavra ganha contorno, densidade, profundidade, sentido. Na sombra, a palavra não se projeta à imagem do silêncio, mas sim, "à imagem do calar", como no verso do poema "Mecha" [Strähne], do mesmo livro. ${ }^{39}$ E calar também é um modo de romper o silêncio, é dizer em silêncio. E é justamente na medida em que se realiza como um dizer sem dizer que o calar tem também a densidade da sombra: é o próprio modo de falar sem "separar o Não do Sim”, sem separar a escuridão da luz.

\footnotetext{
${ }^{36}$ Vide nota 18.

${ }^{37}$ Apesar de economicamente menos confortável para a prática de tradução de poesia, as traduções feitas aqui optam pelo uso sistemático do "você", com as formas verbais de seu uso corrente, mas com os pronomes da segunda pessoa gramatical (teu, tua). A ideia, aqui, é evitar a associação automática da obra de Celan com certo "lugar comum do poético", lugar que, na variante brasileira do português contemporâneo, o uso sistemático da forma pronominal tu não evoca necessariamente, mas pode evocar. $\mathrm{Na}$ perspectiva crítica que instrui este trabalho, esse "lugar comum" é um dos lugares de que a obra de Celan parece insistir em se afastar.

38 "Sprich - / Doch scheide das Nein nicht vom Ja. / Gib deinem Spruch auch den Sinn: / gib ihm den Schatten". (CELAN 2002: 103).

${ }^{39}$ Trata-se do segundo verso da terceira estrofe: "uma palavra à imagem do calar" [ein Wort nach dem Bilde des Schweigens]. (CELAN 2002: 21)
} 
A luz, em Celan, está a serviço dessa "obscuridade constitutiva do poema". Num dos aforismos de Contraluz [Gegenlicht], publicado postumamente, Celan reforça o sentido da luz como tensão que instaura a escuridão: "Não se engane: não é que esta última lâmpada dê mais luz - foi o escuro ao redor dela que em si se tornou mais profundo". ${ }^{40}$ E a luz, contraparte do obscuro, é também uma figuração do outro, a contraparte do eu numa visada dialógica, como lemos no poema "Lusco-forme" [Zwiegestal], igualmente do livro De limiar em limiar:

Seja teu olho no quarto uma vela, o olhar, um pavio, seja eu cego o bastante, para incendê-lo. ${ }^{41}$

O olho do outro é a luz que ilumina o eu imerso na escuridão do quarto. E é somente a partir dessa luz, a partir do olhar do outro, que o eu se projeta em sua profundidade e densidade; é a partir do outro que o eu ganha contorno, sombra, sentido. É na relação eu-tu, no sentido mesmo da proposição buberiana - uma referência importante para Celan $^{42}$-, que o eu se constitui como eu; que o eu funda sua própria condição de existência.

Assim, o dialógico e o obscuro se cruzam, em Celan, dramatizando, no espaço do poema, a condição de existência da poesia como condição de existência do homem. Ao ter lugar no poema, a condição humana é dramatizada como morada das sombras, domínio do obscuro. E nesse ter lugar obscuro da existência humana, o outro é o lume que nos dá sentido: não como revelação, mas como tensão que gera o espaço de sombras em que o eu ganha corpo, profundidade. É à luz do outro, de escuro em escuro, que se dá a possibilidade da travessia, da tradução, como parece sintetizar o poema "De escuro em escuro" [Von dunkel zu dunkel], do livro já referido:

\footnotetext{
40 "Täusche dich nicht: nicht diese letzte Lampe spendet mehr Licht - das Dunkel rings hat sich in sich selber vertieft." (CELAN 2000: 165)

41 "Lass dein Aug in der Kammer sein eine Kerze, / den Blick einen Docht, / lass mich blind genug sein, / ihn zu entzünden". (CELAN 2002: 25).

${ }^{42}$ Ao lado da obra de filósofos como Martin Heidegger e de intelectuais de tradição judaica, como Gershom Scholem, Martin Buber integra o repertório frequente de leituras de Celan, especialmente ao longo da década de 50 (FELSTINER 2000: 133). Para uma problematização da relação eu-tu de matriz buberiana, em Celan, vide, entre outros: LÉVINAS 2002; ENCARNAÇÃO 2007.
} 
Cardozo, M. M. - A obscuridade do poético em Paul Celan

\section{DE ESCURO EM ESCURO}

Você abriu os olhos - vejo viver meu escuro.

Vejo-o profundo:

onde é meu e também vive.

Há través? E que nisso desperte?

De quem o lume que me segue os passos,

e que aqui canoeiro? ? $^{43}$

\section{Considerações finais}

Nos fragmentos de seu projeto de conferência, Celan parte em defesa de uma obscuridade do poético. E esse poético, das Dichterische de que fala o poeta, adquire, no ensaio de HEIDEGGER (2005) sobre o famoso verso de Hölderlin - "poeticamente o homem habita" -, a dimensão da própria condição humana do habitar: o poético tornase, assim, condição da existência.

Ora, se, para Heidegger, ${ }^{44}$ com Hölderlin, é poeticamente que o homem habita, em Celan essa condição poética do habitar assume a densidade do obscuro: o obscuro torna-se a lei do espaço habitado poeticamente. Vale lembrar: para Tanizaki, é na penumbra, nas sombras da morada (na morada das sombras) que os objetos ganham profundidade e densidade - banir as sombras representaria o mesmo que reverter a morada à condição de espaço vazio. Nesse triângulo Hölderlin-Heidegger-Celan inscrevem-se os motivos da morada, do poético e do obscuro: o poema ganha, assim, a profundidade e a densidade da existência na condição humana, ${ }^{45}$ de um existir poeticamente, de um poexistir.

\footnotetext{
43 "Du schlugst die Augen auf - ich seh mein Dunkel leben. / Ich seh ihm auf den Grund: / auch da ists mein und lebt. // Setzt solches über? Und erwacht dabei? / Wes Licht folgt auf dem Fuss mir, / dass sich ein Ferge fand?" (CELAN, 2002: 31)

${ }^{44}$ A propósito da complexa relação, pessoal e intelectual, entre Heidegger e Celan, vide, entre outros: GELLHAUS 2002; FRANCE-LANORD 2004; ANDRÉ 2003.

${ }^{45}$ Estão implicadas também, nessa densidade, todas as formas de experiência e, no caso da obra de Celan, a experiência atravessada pelo horror e pela catástrofe da Shoah, como tão bem mostra a pesquisa sobre Celan desenvolvida no contexto dos estudos de Literatura de Testemunho, que a perspectiva adotada neste trabalho não ignora, mas não discute mais centralmente. $O$ trabalho de Mariana Camillo de OLIVEIRA (2011), citado anteriormente, dialoga centralmente com esse viés de estudo da obra de Celan.
} 


\section{Cardozo, M. M. - A obscuridade do poético em Paul Celan}

E obscuro, em Celan, também não se resume a um jogo de enigmas dados a deduções, na mesma medida em que a existência parece se nos impor menos como horizonte de desvelamento de seus mistérios, do que como desafio de enfrentamento de sua condição - por vezes, do horror dessa condição. Que há enigmas, segredos, mistérios, não há o que questionar. Que tais enigmas sejam objeto de uma certa suspensão também parece muito plausível, na medida em que cada enigma prefigura o instante que sucede o passo anterior e antecede o próximo. Mas se não cabe decifrá-los, o que fazer diante desses enigmas, desses mistérios?

Para Celan, como para Derrida, em Schiboleth (DERRIDA 1987), ${ }^{46}$ não se trata de, num afã hermenêutico e totalizador, solucionar, exaurir, esgotar o enigma (DERRIDA 1987: 21). Trata-se, antes, de reconhecer uma "manifestação enigmática do enigma enquanto tal" (DERRIDA 1987: 22), de reconhecer, no espaço do poema, a condição de existência como uma condição enigmática. Trata-se, nesse sentido, de um enigma que é segredo somente na medida em que se apresenta na condição de segredo, mas que, para além disso, não se quer decifrado, descoberto, revelado, solucionado, no sentido de um horizonte que pudesse ser alcançado, de uma falta que pudesse ser estancada, resolvida no movimento dessa busca.

O obscuro, no poema celaniano, dramatiza o enigma da existência, que, se definido dialogicamente, é também o enigma da coexistência, da densidade e complexidade da relação entre um eu e um outro (um tu, um você). No poema “Convívio" (ANDRADE 2004: 287), do Drummond de Claro Enigma, livro de 1951, lemos, a propósito da figura dos outros como enigma, de seu afã de desvelamento e da condição em que tem lugar a relação eu-outros:

Há que renunciar a toda procura.

Não os encontraríamos, ao encontrá-los.

Ter e não ter em nós um vaso sagrado,

um depósito, uma presença contínua,

Para uma discussão mais ampla das questões da Literatura de Testemunho, em geral, vide, entre outros: SeligmanN-Silva 2003; NeSTROVSKI; SeligmanN-SilVA 2000.

${ }^{46}$ Para a íntegra da conferência de Derrida, em tradução para a língua alemã, vide: DERRIDA 1986. Para uma ampliação da reflexão de Derrida sobre a obra de Celan, vide, em tradução para a língua inglesa: DERRIDA 2005 e 2009. Para uma discussão da leitura que Derrida faz de Celan, numa visada ética, vide: VRIES 1992. 


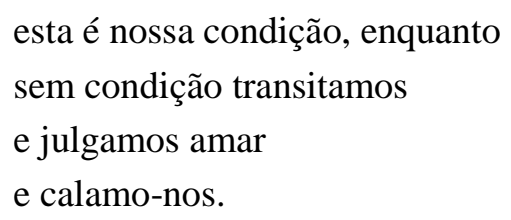

Ou ainda: "Não decifres o enigma. Olha, o mistério / translumina o rosto que está sério" (ANDRADE 2004: 385), como lemos nas "Dedicatórias" do Drummond de Viola de Bolso, livro de 1952. A obscuridade do poema celaniano revela, no que ela tem de enigmático, sua condição de claro enigma: ${ }^{47}$ de enigma que não se impõe de modo esfingético, à demanda de solução, mas, sim, que se expõe como enigma, "na condição dos enigmas", para lembrar também do Drummond de Novos Poemas - livro publicado em 1948 e que antecede o próprio Claro Enigma. Em "O enigma" (ANDRADE 2004: 242-243), texto que encerra esse livro, lemos:

\begin{abstract}
Mas a coisa sombria - desmesurada, por sua vez - aí está, à maneira dos enigmas que zombam da tentativa de interpretação. É mal de enigmas não se decifrarem a si próprios. Carecem de argúcia alheia, que os liberte de sua confusão amaldiçoada. E repelem-na ao mesmo tempo, tal é a condição dos enigmas.
\end{abstract}

No enigma, que ao mesmo tempo impõe um movimento e a ele resiste, a condição de existência manifesta-se como lei, como verdade que irrompe, impele-nos a dar o próximo passo, mas resiste à lógica da redução, de uma solução final, definitiva, instaurando a tensão que faz o poema acontecer, instaurando o espaço em que o poema tem lugar, poexiste, “a provar a nós mesmos que, vivendo / estamos para doer, estamos doendo" (ANDRADE 2004: 305), como num dos últimos dísticos do poema "Relógio do Rosário", que encerra o livro Claro Enigma.

\footnotetext{
${ }^{47}$ Cabe, aqui, fazer uma ressalva quanto à complexidade dessa relação, especialmente no que diz respeito às diferenças de contexto histórico e político em que a vida e a obra de Drummond e de Celan se inscrevem. Diferenças que, aliás, estendem-se até mesmo à questão da obscuridade, uma vez que, se para o poeta de língua alemã a obscuridade do poema é "congênita", "constitutiva", para Drummond, as figurações do obscuro parecem surgir como elemento externo. Ao menos é o que se pode ler logo na primeira estrofe de "Dissolução", primeiro poema de Claro Enigma, em que "escurece", "o dia finda" e, diante disso, o eu "aceita a noite" (ANDRADE 2004: 247); ou, ainda, no caso da "forma obscura" que surge de repente e "barra o caminho das pedras" em "O enigma" (ANDRADE 2004: 242-243), último poema de Novos Poemas. Arrisco aqui, portanto, uma relação que pode ser tão produtiva quanto delicada e que só poderá ser desenvolvida adequadamente no contexto de outro ensaio. Ainda que a cautela recomendasse calá-la neste contexto, assumo o risco de apontá-la.
} 
Tanizaki relata-nos que seus ancestrais delimitavam em quatro lados e no topo uma determinada área luminosa da superfície terrestre e o faziam para criar seu "mundo de sombras" (TANIZAKI 2007: 50). O homem moderno, no entanto, habituado há muito com o mundo da luz elétrica, teria esquecido ou perdido a dimensão das sombras em sua vida cotidiana (Id.: 53). Em razão disso, seria necessário, segundo o escritor japonês, realizar um movimento que teria em vista "chamar de volta, pelo menos ao campo literário, esse mundo de sombras que estamos prestes a perder” (Id.: 63). Celan, a seu modo, parece fazê-lo.

Para Celan, o poema traduz-se como a obscuridade que tem lugar na própria condição humana, representa-a não apenas na discursividade das figurações do real, mas como dramatização tópica tanto de sua densidade quanto do que não encontra passagem à representação. O poema, para Celan, não recalca a parte noite das "palavras sondadoras no silêncio", as "palavras à imagem do calar", as palavras que "dizem suas sombras”, para usar aqui figuras do próprio poeta. Como na morada de Tanizaki, o poema, para Celan, tem lugar como um grande pedaço de sombra, e é o obscuro, na morada das sombras, que dá ao poema contornos de singularidade.

\section{Referências bibliográficas ${ }^{48}$}

ARON, Irene. Paul Celan: a expressão do indizível. In: Pandemonium Germanicum (1), 1997, p.77-85

Alleman, Beda. Paul Celans Sprachgebrauch. In: COLIN, Amy D. (org.). Argumentum e Silentio: International Paul Celan Symposium. Berlim, Walter de Gruyter, 1987, 3-15.

Andrade, Carlos Drummond de. Poesia Completa. Rio de Janeiro, Nova Aguilar, 2004.

ANDRÉ, Robert. Gespräche von Text zu Text: Celan, Heidegger, Hölderlin. Hamburg, Meiner, 2003.

Barbosa, João Alexandre. A comédia intelectual de Paul Valéry. São Paulo: Iluminuras 2007.

BENN, Gottfried. Probleme der Lyrik. In: Völker, Ludwig (org.). Theorie der Lyrik. Stuttgart, Reclam, 1986, p.65-69.

CANTINHO, Maria João. Fora de moda. In: Crítica [revista de filosofia]. http://criticanarede.com/html/lds_seterosas.html (03/05/2006).

Paul Celan: no rastro perdido da experiência. In: Literatura pnet. http://www.pnetliteratura.pt/cronica.asp?id=2915 (15/12/2010).

\footnotetext{
${ }^{48}$ Sou grato aos pareceristas desta Revista pelas valiosas sugestões, que muito contribuíram para a revisão final deste ensaio.
} 
CARdozo, Mauricio Mendonça. Paul Celan: a poesia depois de Auschwitz. In: Revista Coyote (14), 2006, p.2-7.

Paul Celan: prática e espaço da poesia contemporânea. In: Revista Letras (48:1), 2008, p.145-155.

CArone, Modesto. A poética do silêncio: João Cabral de Melo Neto e Paul Celan. São Paulo, Perspectiva, 1979.

Paul Celan: a linguagem destruída. In: Banco de dados folha. http://almanaque.folha.uol.com.br/carone2.htm, publicado em 1973 (15/03/2012).

Celan, Paul. Mikrolithen sinds, Steinchen. Die Prosa aus dem Nachlass, edição crítica organizada e comentada por Barbara Wiedemann e Bertrand Badiou. Frankfurt, Suhrkamp, 2005.

Mohn und Gedächtnis. Vorstufen, Textgenese, Endfassung, edição crítica de Tübingen, organizada por Jürgen Wertheimer em colaboração com Heino Schmull e Christiane Braun. Frankfurt, Suhrkamp, 2004.

Die Gedichte. Kommentierte Gesamtausgabe in einem Band, organizada e comentada por Barbara Wiedemann. Frankfurt, Suhrkamp, 2003.

Von Schwelle zu Schwelle. Vorstufen, Textgenese, Endfassung, edição crítica de Tübingen, organizada por Jürgen Wertheimer em colaboração com Heino Schmull, Christiane Braun e Markus Heilmanni. Frankfurt, Suhrkamp, 2002. . Gesammelte Werke in sieben Bänden, volume III. Frankfurt, Suhrkamp, 2000.

Der Meridian. Endfassung, Entwürfe, Materialien, organizado por Bernhard Böschenstein e Heino Schmull. Frankfurt, Suhrkamp, 1999.

Arte Poética: O Meridiano e outros textos, tradução de João Barrento e Vanessa Milheiro, posfácio e notas de João Barrento. Lisboa, Cotovia, 1996a.

Die Niemandsrose. Vorstufen, Textgenese, Endfassung, edição crítica de Tübingen, organizada por Jürgen Wertheimer, em colaboração com Heino Schmull e Michael Schwarzkopf. Frankfurt, Suhrkamp, 1996b.

Hermetismo e Hermenêutica, introdução, tradução, comentários e organização de Flávio Kothe. Rio de Janeiro, Tempo Brasileiro, 1985. 1977.

Poemas, tradução e introdução de Flávio Kothe. Rio de Janeiro, Tempo Brasileiro,

DERRIDA, Jacques. Schibboleth: Für Paul Celan, tradução de Wolfgang Sebastian Baur. Graz; Viena, Böhlau, 1986.

Schibboleth. In: Colin, A. D. (Hg.). Argumentum e Silentio: International Paul Celan Symposium. Berlim, Walter de Gruyter, 1987, 16-42.

Sovereignties in Question: The Poetics of Paul Celan, organizado por Thomas Dutoit

e Outi Pasanen. Nova Iorque, Fordham University Press, 2005.

The Beast \& the Sovereign, volume 1, organizado por Michel Lisse, marie-Louise Mallet e Ginette Michaud; tradução de Geoffrey Bennington. Chicago; Londres, The University of Chicago Press, 2009.

EnCARnAÇÃO, Gilda. 'Fremde Nähe': Das dialogische als poetisches und poetologisches Prinzip bei Paul Celan. Wiesbaden, Königshausen \& Neumann, 2007.

Felstiner, John. Paul Celan: Eine Biographie, tradução de Holger Fliessbach. München, C. H. Beck, 2000.

France-LanORD, Hadrien. Paul Celan et Martin Heidegger: Le sens d'um dialogue. Paris, Fayard, 2004.

FRIEDRICH, Hugo. Die Struktur der Modernen Lyrik: Von der Mitte des neunzehnten bis zur Mitte des zwanzigsten Jahrhunderts. Hamburg, Rowohlt, 2006.

Gellhaus, Axel. '...seit ein Gespräch wir sind...': Paul Celan bei Martin Heidegger in Todtnauberg. Frankfurt, Suhrkamp, 2002. 
GUERreIRo, António. Caminhos para o exílio. In: Primeiras edições. www.primeirasedicoes.expresso.pt/ed1336/c402.asp (03/05/2006).

HaRbusCh, Ute. Gegenübersetzungen: Paul Celans Übertragungen französischer Symbolisten. Göttingen, Wallstein Verlag, 2005.

HeIDEGGER, Martin. ...poeticamente o homem habita. In: Ensaios e Conferências, tradução de Emmanuel C. Leão, Gilvan Fogel e Márcia Sá Cavalcante S. Petrópolis, Vozes, 2005, 165181.

LÉvinAS, Emmanuel. Paul Celan: de l'être à l'autre. Saint-Clément-de-Rivière, Fata Morgana, 2002.

LiNS, Vera. Paul Celan, na quebra do som e da palavra: poesia como lugar de pensamento. In: Poesia e Crítica: uns e outros. Rio de Janeiro, 7Letras, 2005, 23-34.

NeSTRovski, Arthur; Seligmann-Silva, Márcio (Org.). Catástrofe e representação. São Paulo, Escuta, 2000.

OliveirA, Mariana Camilo de. A dor dorme com as palavras: a poesia de Paul Celan nos territórios do indizível e da catástrofe. Dissertação de mestrado. FALE/UFMG, Belo Horizonte, 2008.

. A dor dorme com as palavras. Rio de Janeiro, 7letras, 2011.

PEREZ, Juliana Pasquarelli. Offene Gedichte: Eine Studie über Paul Celans Die Niemandsrose. Tese de doutorado. FFLCH/USP, São Paulo, 2005.

Offene Gedichte: Eine Studie über Paul Celans Die Niemandsrose. Würzburg, Königshausen \& Neumann, 2010.

RosA, João Guimarães. Grande Sertão: veredas. Rio de Janeiro, Nova Fronteira, 1988.

Rosenthal, Erwin Theodor. Celan e a procura pelo 'poema absoluto'. In: Estadão. http://www.jt.estadao.com.br/noticias/99/09/11/sa8.htm, publicado em 1999 (03/05/2006).

SeligmanN-Silva, Márcio (Org.). História, memória, literatura: o testemunho na era das catástrofes. Campinas, Ed. Unicamp, 2003.

SISCAR, Marcos Antonio. Os amores amarelos, tradução e introdução de Marcos Siscar. São Paulo, Iluminuras, 1996.

. O inferno da tradução. In: CARDOZo, Mauricio Mendonça; WeINHARDT, Marilene (org.). Centro, Centros: Literatura e Literatura Comparada em Discussão. Curitiba, Editora UFPR, 2011, p.81-94

TANIZAKI, Junichiro. Em louvor da sombra, tradução de Leiko Gotoda. São Paulo, Companhia das Letras, 2007.

VALÉRY, Paul. Variedades, organização e introdução de João Alexandre Barbosa; tradução de Maiza Martins de Siqueira; posfácio de Aguinaldo Gonçalves. São Paulo: Iluminuras 2007.

VRIES, Hent de. Le Schibbolteh de l'étique : Derrida avec Celan, tradução do alemão de Hélène Charpiat et Jean-Michel Rabaté. In: RABATE, Jean-Michel; WeTZEL, Michael (org.). Donner la mort. L'éthique du don : Jacques Derrida et la pensée du don. Colloque de Royaumont, Abbaye de Royaumont, 9 décembre 1990. Paris, Métailié, 1992, p.212-238.

Recebido em 29/03/2012

Aprovado em 30/04/2012 